\title{
Kadın Mülteciler Sosyal Uyumu Rekreasyonla Aşıyor*
}

\author{
Melike ESENTAŞ ${ }^{1+}$ (D), Rabia Gülten GÜVEN ${ }^{(D)}$ Pınar GÜZEL $^{1}$ \\ ${ }^{1}$ Manisa Celal Bayar Üniversitesi, Spor Bilimleri Fakültesi, Manisa.
}

\section{Orijinal Makale}

Gönderi Tarihi: 02.01.2020
Kabul Tarihi: 25.03.2020
DOI: $10.25307 /$ jssr.679285

Online Yayın Tarihi: 30.06 .2020

\section{Öz}

Suriye iç savaşı sonrası Türkiye'ye gelen kadın mültecilerin sosyal uyum süreçlerinde rekreasyonun ne yönde etki sağladığını durum çalışması ile tespit etmek bu araştırmanın amacını oluşturmaktadır. Araştırmada nitel araştırma veri toplama yöntemlerinden birisi olan görüşme yöntemi kullanılmıştır. Araştırmanın çalışma grubunu rekreatif etkinliklere katılım sağlayan 18 kadın mülteci oluşturmaktadır. Katılımcılar amaçlı örneklem yöntemlerinden ölçüt örnekleme ile seçilmiştir. Araştırmada veri toplama aracı olarak araştırmacılar tarafından geliştirilen yarı yapılandırılmış görüşme formu kullanılmıştır. Veriler betimsel ve sonrasında içerik analizi yöntemleri kullanılarak incelenmiş ve bu süreçte Nvivo 10 nitel analiz programı kullanılarak uygun temalar altında kodlanmıştır. Elde edilen verilerin analizine bakıldığında kadın mültecilerin görüşleri "psikolojik", "fizyolojik" ve "sosyal” çıktılar şeklinde 3 (üç) tema altında toplandığı görülmüştür. Yapılan bu araştırmamızın sonuçlarına göre; kadın mültecilerin katılmış oldukları rekreatif etkinlikler aracılığıyla sosyal uyumda geçiş sürecinin kolaylaştırılmasında "rekreasyon"un önemli bir role sahip olduğu tespit edilmiştir. Bu araştırma sonuçlarının kamu ve özel sektör kuruluşlarına önemli bir veri olduğu düşünülmekte olup, mülteci gruplarına yönelik rekreatif etkinliklerin hazırlanıp, uygulanması ve desteklenmesi önerilmektedir.

Anahtar kelimeler: Mülteciler, Kadın mülteciler, Sosyal uyum, Rekreasyon.

\section{Female Refugees Get through the Social Adaptation with Recreation}

\begin{abstract}
Determining how the recreation affected the social adaptation processes of female refugees who came to Turkey following the civil war in Syria with a case study constitutes the purpose of this research. Interview technique being among the qualitative research techniques was used in the research. 18 female refugees participating in recreative activities are the study group of the research. Participants were selected with criterion sampling being among the purposeful sampling methods. The semi-structured interview form developed by the researchers was used as a data collection tool. Data were analyzed with descriptive and content analysis methods and in this process, they were coded under the appropriate themes by using Nvivo 10 qualitative analysis program. Concerning the analysis of data obtained, the opinions of female refugees are observed to be collected under 3 (three) themes namely "psychological", "physiological" and "social". The results of this study indicate that "recreation" has an important role in facilitating the social adaptation process of female refugees through the recreative activities they participate. The results of these surveys are considered to be important data for public and private sector institutions and it is recommended to prepare, implement and support recreational activities for refugee groups.
\end{abstract}

Keywords: Refugees, Female refugees, Social adaptation, Recreation.

*21-24 Mart 2019 tarihinde II. Dünya Spor Bilimleri Araştırmaları Kongresi'nde sözel bildiri olarak sunulmuştur.

${ }^{\dagger}$ Sorumlu yazar: Doç. Dr. Melike ESENTAŞ, E-posta: melike.esentas@windowslive.com 


\section{GíRiş}

Dünyanın farklı yerlerinde yaşanmış ve yaşanmakta olan savaşlar, sorunlar ve çatışmalar nedeniyle birçok insan yaşadığı ülkesini terk etmektedir. Mülteci “ırk, din, tabiiyet, belirli bir toplumsal gruba üye olması ya da siyasi düşüncelerinden dolayı kendi ülkelerinde yaşayamayan, yaşamaktan korkan ve bunlardan dolayı ülkesini terk eden veya terke zorlanan kişi” olarak ifade edilmektedir (Özkarsl1, 2014). Mülteci bir birey olmak kişinin kendi tercihi olabilmekle birlikte kendi iradesi dışında da gerçekleşebilmektedir.

Mültecilerin göçe maruz kalmalarının sonucunda psikolojik, ekonomik, barınma, iletişim vb. gibi birçok konuda güçlük yaşadığı yapılan çalışmalardan da anlaşılmaktadır (Erdem, 2017; Orhan ve Senyücel Gündoğar, 2015). Kendi vatanından, yaşamından ayrılmak zorlu bir süreç iken, özellikle dezavantajlı gruplardan birisi olan kadınlar için mülteci olmanın daha zor olduğu düşünülmektedir. Kadın mültecilerin göçle birlikte mücadele etmek zorunda oldukları sorunlardan bir tanesi de sosyal uyum sürecidir. Sosyal uyum, bireylerin alışmış oldukları çevreleri ile uyum içinde yaşıyor olmalarıdır. Türk Dil Kurumu'na (TDK) göre sosyal uyum, toplumsal çevreye veya bir duruma uyma, uyum sağlama, intibak, entegrasyon anlamına gelmektedir (TDK, 2019). Diğer bir anlamı ile bireyin toplumsallaşmasıdır. Toplumsallaşma ise, bireyin kişilik kazanarak belli bir toplumsal çevreye hazırlanması, toplumla bütünleşmesi süreci, sosyalleşmesi olarak da ifade edilmektedir (TDK, 2019). İçinde yaşadığımız topluma, bireylere karşı sorumluluklarımız bulunmaktadır. $\mathrm{Bu}$ nedenle, farklı kültürlere, çeşitli gruplara, etnik kökenleri her ne olursa tüm bireylere insan hakları çerçevesinde saygılı olarak birlikte yaşamak ve/veya yaşamaya çalışmak o toplumun refahı açısından büyük bir önem arz etmektedir. Bu nedenle bu çalışma özelinde yer alan kadın mülteciler düşünüldüğ̈nde; kendi iradeleri ile ya da zorunlu geldikleri Türkiye'ye uyum sağlamalarının oldukça önemli olduğu düşünülmektedir.

Sosyal uyum sürecinde bireylerin kendilerini iyi hissetmelerinde psikolojik, fiziksel ve sosyal faydaların kazanılması açısından önemli bir yere sahip rekreasyon etkinliklerinin kolaylaştırıcı bir etmen olduğu söylenebilir. Mülteciler kimlik oluşturma ve topluma uyum sağlama sürecinde zorladıklarında serbest zamanın rollerinden olan özümseme, bütünleştirme ve zorluklarla başa çıkma gibi serbest zaman kazanımları etkileyici ve çözüm sağlayıcı bir rol üstlenmektedir (Codesal, Peperkamp ve Tiesler, 2015). Simmons'a (2000) göre rekreasyon; kişinin yenilenmesinde etkili olan sosyal bir etkinlik olarak tanımlamaktadır (Brey ve Lehto, 2007). Rekreatif etkinliklere olan ihtiyaç günden güne daha da artmaktadır. Tütüncü vd., (2011) yaptıkları çalışmada rekreatif etkinliklere katılım sağlayan bireyin yaşamda olumsuzluklardan arınma, özgüven kazanma ve sosyo-kültürel uyum sürecini kolaylaştırmada olumlu katkılarının olduğunu tespit etmişlerdir. Rekreasyonel etkinlikler, bireysel açıdan; fiziksel sağlık, ruhsal iyi oluş, sosyalleşme, yenilikçilik-yaratıcılık, var olan beceri ve yeteneğin geliştirilmesi, çalışma hayatında performansın artması ve bireyin mutlu olması gibi katkılar sağlamaktadır. Bu bağlamda; Suriye iç savaşı sonrası Türkiye'ye gelen kadın mültecilerin sosyal uyum süreçlerinde rekreasyonel etkinliklerin rolünü durum çalışması ile tespit etmek bu araştırmanın amacını oluşturmaktadır. 


\section{METOT}

Araştırma kadın mültecilerin sosyal uyum süreçlerinde rekreasyonel etkinliklerin rolünü incelemeye yönelik nitel bir çalışmadır. Çalışmada durum analizi deseninden yararlanılmıştır. Durum analizi; bir ya da birden fazla olayın, ortamın, programın, sosyal grubun ya da diğer birbirlerine bağlı sistemlerin derinlemesine incelendiği yöntemdir (Büyüköztürk vd., 2017). Çalışma grubunu rekreatif etkinliklere katılım sağlayan ve çalışmaya gönüllü katılım sağlayan18 kadın mülteci oluşturmaktadır.

$\mathrm{Bu}$ araştırmanın örneklemini oluşturan çalışma grubundaki katılımcıların demografik bilgisine Tablo 1'de yer verilmiştir. Katılımcılar, amaçlı örneklem yöntemlerinden ölçüt örnekleme yöntemi ile seçilmiştir. "Ölçüt örneklemede, gözlem birimleri belli niteliklere sahip kişiler, olaylar nesneler ya da durumlardan oluşturulabilir. Bu durumda örneklem için belirlenen ölçütü karşılayan birimler örnekleme alınır" (Büyüköztürk vd., 2008). Bu araştırmada da ülkelerinde yaşanılan olaylar durumuyla Türkiye'ye gelen Suriyeli kadın mülteci olması bir diğeri ise çalışmaya gönüllü olarak katılım sağlamasıdır.

Tablo 1. Katılımcıların kişisel bilgileri

\begin{tabular}{|c|c|c|c|c|c|c|}
\hline Katılımcilar & Yaş & $\begin{array}{l}\text { Eğitim } \\
\text { Durumu }\end{array}$ & $\begin{array}{l}\text { Medeni } \\
\text { Durum }\end{array}$ & Meslek & $\begin{array}{l}\text { Suriye'de rekreatif } \\
\text { etkinliklere katılım }\end{array}$ & $\begin{array}{c}\text { Sosyal çevre } \\
\text { rekreasyonel } \\
\text { etkinliklere katılımı }\end{array}$ \\
\hline K1 & 30 & İlkokul & Evli & Ev hanımı & Hayır & Aile bireyi \\
\hline K2 & 29 & İlkokul & Evli & Ev hanımı & Hayır & Arkadaş \\
\hline $\mathbf{K 3}$ & 20 & Lise & Bekar & Çalıșmıyor & Hayır & Arkadaş \\
\hline K4 & 25 & İlkokul & Bekar & Kuaför & Hayır & - \\
\hline K5 & 28 & Lise & Evli & Sekreter & Hayır & - \\
\hline K6 & 22 & Ortaokul & Evli & Ev Hanımı & Hayır & Aile bireyi \\
\hline K7 & 27 & İlkokul & Bekar & Tekstil & Hayır & Arkadaş \\
\hline K8 & 35 & Lise & Evli & Kuaför & Evet & - \\
\hline K9 & 24 & Üniversite & Bekar & Çalışmıyor & Evet & Aile bireyi \\
\hline K10 & 26 & Ortaokul & Evli & Ev Hanımı & Hayır & Aile bireyi \\
\hline K11 & 30 & Lise & Evli & Kuaför & Hayır & Arkadaş \\
\hline K12 & 27 & Lise & Evli & Ev Hanımı & Hayır & - \\
\hline K13 & 40 & Ortaokul & Evli & Ev Hanımı & Hayır & Aile bireyi \\
\hline K14 & 29 & Lise & Evli & Ev Hanımı & Hayır & - \\
\hline K15 & 42 & Ortaokul & Bekar & Ev Hanımı & Hayır & - \\
\hline K16 & 28 & Ortaokul & Evli & Ev Hanımı & Hayır & Aile bireyi \\
\hline K17 & 24 & Ortaokul & Bekar & Öğrenci & Hayır & - \\
\hline K18 & 20 & Lise & Bekar & Sporcu & Evet & - \\
\hline
\end{tabular}

$\mathrm{Bu}$ çalışmada veri toplama aracı olarak araştırmacılar tarafından geliştirilen yarı yapılandırılmış görüşme formu kullanılmış ve bireysel görüşmeler yöntemi uygulanmıştır. Gerçekçi sonuçlara ulaşma adına araştırmacı, bireysel ya da grupla yapılabilecek olan görüşme türlerinden duruma uygun bir şekilde herhangi birisini ya da ikisini kullanabilir (Yıldırım ve Şimşek, 2013). Araştırmacılar tarafından hazırlanan görüşme sorularına ilişkin ilk olarak literatür taraması yapılmış, sonrasında da Suriyeli kadın mülteciler ile çalışmakta olan 1 eğitmen ve alanında uzman 2 öğretim üyesinin görüşleri alınarak sorular son haline getirilmiştir. Görüşme formu; 1)Sosyal çevreye uyum sağlarken zorlandınız mı? 2)Katılmış olduğunuz bu rekreatif etkinliklerin size kazanımları nelerdir? 3)Yaptığınız rekreatif etkinlikler Türkiye'ye uyum sürecinizi nasıl etkiledi? Sorularına yanıt aranmıştır. Hazırlanan görüşme formu ölçüt örnekleme yöntemi ile belirlenmiş olan katılımcı grubuna uygulanmıştır. Kadın mültecilere araştırmanın amacı aktarılmış ve verilerin tamamen bilimsel amaçı kullanılacağı hakkında açıklama yapılmıştır. Çalışmamıza katılımcılar gönüllülük 
esasıyla dâhil olmuş olup, her birisinden gerekli izinlerden alınmıştır. Katılımcılarla araştırmacının uygun olarak belirlemiş oldukları gün ve saatlerde rekreatif etkinlerin düzenlendiği alanda bireysel görüşmeler yapılmış olup, veriler ses kayıt cihazı ile de kaydedilmiştir.

Araştırmanın nitel bir çalışma olması ve veri toplama aracının açık uçlu sorulardan oluşması sebebiyle katılımcılardan elde edilen veriler öncelikle Office programına aktarılmıştır. Bu verilerin değerlendirilmesinde içerik analizi yapılarak açık kodlama yöntemine başvurulmuştur (Yıldırım ve Şimşek, 2013). Araştırma bulgularının ana hatlarını oluşturacak temalar için Nvivo 10 Nitel Analiz Programı kullanılarak temalara ilişkin içerik analizi yapılmıştır.

\section{BULGULAR}

Elde edilen verilerin analizine bakıldığında kadın mültecilerin görüşleri "psikolojik", “fizyolojik” ve "sosyal” çıktılar şeklinde 3 (üç) tema altında toplandığı görülmüştür.

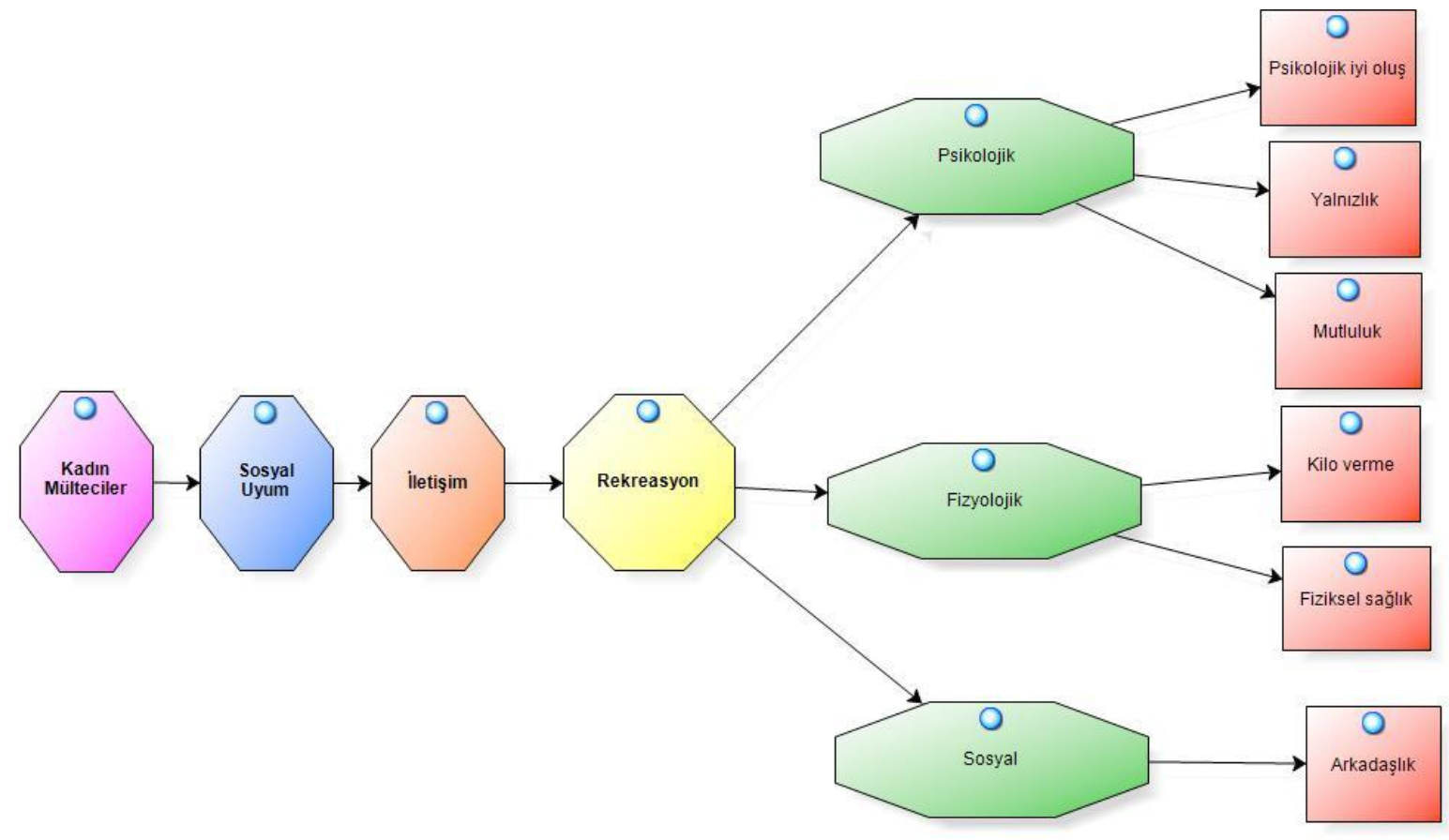

Model 1. Kadın mültecilerin sosyal uyum ve rekreasyon ilişkisi

$\mathrm{Bu}$ alt temalara ilişkin katılımcıların görüşleri aşağıda verilmiştir.

"Buraya ilk geldiğimde en büyük sıkıntıyı tabi ki dilde yaşadım. Çocukların okullarında sorunlar yaşadım. Hangi okula gidecekler, ne yapacă̆ım diye düşünmüşü̈m. Çok zordu benim için. Çocukların derslerinde zorluklar yaşadım. İletişim sorununu dil kursuna giderek çözmeye çalışlyorum. Henüz çözebilmiş değilim ama kendim alışverişe çıkabiliyorum. Yavaş yavaş alışıyorum” (K2). 
"Türkiye'ye geldiğimde her şey zordu benim için bilmediğim bir dil ve insanlar en çok zorluğu bu yönde çektim. Türklerle olan komşuluk ilişkilerimde çok zorlandım. Kabullenmek istemediler. Sokakta yürürken insanların bana baktı̆̆ını fark ediyordum. Dillerini bilmediğim için onlarla iletişime geçemiyordum. 3 senedir burada yaşıyorum zorluklar azaldı ama tamamen bitmiş değil benim için. Buraya gelirken kendimi çok mutlu hissediyorum. Burada spor yapmak benim içimde bir umut oldu geleceğe dair" (K3).

"Önceden burada kendimi çok fazla yalnız hissediyordum. Çünkü ailem yanımda yok ben eşim ve çocuklarımla geldim buraya kendi anne babam yok. Ama spora geldim iyi oldum. Kendimi iyi hissediyorum. Burada arkadaş edindim hepimiz kardeş gibiyiz ama öyle eve falan gitmiyoruz sadece burada görüşüyoruz. Hafifliyorum kilo vermeye başladım. Önceden ă̆ır hissediyordum kendimi çok mutluyum”(K4).

Bir dil sorunu en büyük sorun bu oldu zaten. Dilini bilmiyorsan anlaşamıyorsun. Kendini anlatamıyorsun zaten sorun buradan doğuyor. Ben kendi kendime bir şeyler ögrendim dil ile ilgili kursa da gittim. Ben 2 diploma aldım Türkçe dil kurslarında Türkçe okuma yazma biliyorum artık. Ama konuşurken hala zorlanıyorum sizin kadar rahat iletişim kuramıyorum. Burada katıldı̆̆ım bu etkinlikler aracılı̆̆ıyla daha iyi iletişim kurmama katkı sağlanmış oldu (K7).

"Fiziksel olarak çok değişim oldu. Ben 100 kiloydum çok kilo verdim ve devam ediyorum kilo vermeye. Ben buraya gelmeden önce çok stresliydim stresli bir dönem geçiriyordum yavaş yavaş atmaya başladım hatta attım bile çok iyi geldi bana burası. Psikolojik sıkıntılarım vardı çok sıkıntı çektim bütün gün evde sürekli yemek yiyordum sonra burayı duydum hemen geldim. Bu kadar iyi olacağını düşünmemiştim ben burada fikir olarak bile değiştim. Eskisi gibi çok yemiyorum kilo veriyorum ve mutluyum sadece kilo verdiğim için değil buraya geldiğim içinde. Suriyeli arkadaşlarım var Türk arkadaşlarım da var” (K11).

"Hayat her yönden daha iyi olmaya başladı. Hem artık evden çıkmaya başladım bedenim daha iyi buraya geliyorum artık daha aktif hissediyorum kendimi daha sağlıklı düşünmeye başladım dışarıdaki hayatı görmeye başladım psikolojik olarak da daha iyiyim artık. Daha önce evet yalnızlık hissettim çok mutluyum şimdi” (K12).

"Hem fiziksel olarak hem kişisel olarak hem de arkadaş çevresi olarak bana çok iyi geldi burası. Rutinim alt üsttü buraya başlamadan önce ama daha sonra buraya başladım her şey değişti benim bir spor saatim var o saatte orda olmam gerekiyor diyorum, daha düzenli yaşamaya başladım. Benim yemek saatlerim bile artık çok düzenli. Tanımadığım kişilerle arkadaşlık kurdum hepsini çok sevdim” (K14).

"Illk geldim çok zor her şey biz Türkiye'ye ailece gezmeye gelirdik sonra savaşs çıktı Suriye'de ve temelli gelmek zorunda kaldık ben çok zor günler geçirdim ilk yerleştiğimizde. Çünkü savaşta arkadaşlarımızı ailemizi bıraktık okulumu bıraktım ben Suriye'de atlettim koşuyordum Suriye 2.liğim vardı her şeyi bırakı gelmek zorunda kaldık. Illk geldim Türkçe fazla bilmiyorum bir de arkadaşım yok psikolojim çok bozulmuştu ben 2 yll kendimi eve kapattım. Hiçbir yere gitmedim. Markete bile gitmek istemiyordum. Ölen arkadaşlarım oldu onların acısını çok zor attım. Sonra 
Esentaş, M., Güven, R.G. ve Güzel, P. (2020). Kadın mülteciler sosyal uyumu rekreasyonla aşıyor. Spor Bilimleri Araştırmaları Dergisi, 5(1), 35-43.

ben Kickboksa başladım yavaş yavaş kendimi toparlamaya başladım bana çok iyi geldi. Arkadaş edinmeye başladım. Daha sonra pilatesi duydum oraya geldim benim için umut kaynă̆l yaşama sevinciydi spora gelmek” (K18).

\section{TARTIŞMA VE SONUÇ}

$\mathrm{Bu}$ araştırmanın sonucu olarak, Suriye iç savaşı sonrası Türkiye'ye gelen kadın mültecilerin sosyal uyum süreçlerinde rekreatif etkinliklerin fizyolojik, psikolojik ve sosyal çıktılarının ortaya çıktığı görülmektedir. Savaş sonrası göç nedeniyle kadın mülteciler psikolojik deformasyonda iletişim ve kendilerini yalnız hissetmelerini rekreatif etkinlikler ve gitmiş oldukları Türkçe dil eğitim kursları aracılığıyla aşmaya çalıştıklarını ifade etmişlerdir. Demirbaş ve Bekaroğlu (2013), yapmış oldukları çalışmada mülteci kadınların psikolojik olarak, erkeklerden daha çok olumsuz etkilendiklerini tespit etmişlerdir. Kadın mültecilerin göçten sonra daha kolay sosyal uyum sağladıklarına ilişkin mevcut araştırma sonucu Renner ve Salem (2009) tarafından yapılan çalışma sonuçları ile de örtüştüğü ifade edilebilir. Renner ve Salem (2009) kadınların erkeklere göre daha fazla duygusal patlama ve duygusal kırılganlık gösterdiğini tespit etmiştir. Kadın mültecilerin hem memleketlerinden ayrılmaları hem de yeni bir ülkeye gelmiş olmaları ile birlikte sosyal uyum sağlamaları güçleşmektedir (Angel vd., 2001; Buz, 2008). Lu ve Argly (2001) çalışmalarında; serbest zaman aktivitelerinde belli bir ciddiyet, düzen ve gönüllülük sergileyen kişilerin diğerlerine göre psikolojik iyi oluşlarının, tatminlerinin daha fazla olduğunu belirtmişlerdir. Yapılan araştırmalar bu araştırmamızı destekler niteliktedir. Aynı zamanda, Karadağ ve Altıntaş (2010) tarafindan "mülteciler ve sağlık" adlı çalışmada; sığınmacıların yaşamış olduğu psikolojik sorunun stres bozukluğundan kaynaklandığı bulunmuştur. Kadın mültecilerin kendilerini psikolojik iyi oluşlarında serbest zaman etkinliklerinin önemli olduğu sonucu ile Karadağ ve Altıntaş’ın (2010) çalışmaları ile örtüşmektedir. Özbey vd., (2018) yapmış oldukları çalışmada, bir serbest zaman etkinliği olarak Türkiye'de düzenlenen uluslararası kamp etkinliklerine katılan kız öğrencilerin etkinlikler sonucunda sosyalleşme, duygusal zeka ve psikolojik iyi oluş hallerinde olumlu değişimler olduğunu açıklamışlardır. Bu sonuçlar çalışmamızı destekler nitelikledir.

Sezgin ve Yolcu (2016) göç ile gelen uluslararası öğrencilerle yapmış oldukları çalışmaları sonucunda Suriyeli gençler ile düzenlenecek sportif, sosyal ve kültürel etkinliklerin kültürlerarası etkileşimin artması ve tanıtımı açısından faydalı olacağını öneri olarak sunmuşlardır. Zerengök vd.,'nin (2018) çalışmasında uluslararası öğrencilerde serbest zaman etkinliklerinin sadece sosyal uyum üzerine değil fiziksel ve psikolojik çıktılarının da olduğu sonucuna ulaşılmıştır. Çalışmamızdaki serbest zaman etkinliklerine katılan kadın mültecilerin de olumlu ifadeleri ile serbest zaman rekreasyon etkinliklerinin çoklu kazanımlar sağlamada önemli bir yere sahip olduğu sonucu desteklenmektedir.

Karademir ve Doğan (2019) yılında yapmış oldukları çalışmada Suriyeli kadın mültecilerin sosyal uyumunu zorlaştıran etmenlerden birisi olarak göç ettikleri ülkede hayatlarını idame ettirmekte olan bireylerin kız çocukları ve kadın mültecilere karşı olan bakış açılarının olumsuzluğu olarak tespit etmişlerdir. Esentaş vd., (2017) farklı bölgelerden gelen ve rekreatif içeriklere sahip gençlik kamplarına katılan kız öğrencilerin kampın ilk zamanlarında birbirlerine karşı önyargılı yaklaşmalarına rağmen, uygulanan etkinlikler aracılı̆̆ı ile 
önyargılarının yıkıldığı ve etkili iletişim kurdukları sonuçlarına ulaşılmıştır. Bu çalışmada da bazı kadın mülteciler sosyal yaşamlarını sağlıklı ve mutlu sürdürmek adına çevresindekilerle iletişim kurarken herhangi bir sıkıntı yaşamadıklarını ancak bazıları ise aynı dili konuşamadıkları için iletişim sorunundan ciddi bir düzeyde etkilendiklerini ifade etmişlerdir. Bireylerin birbirlerini ve kültürlerini anlamalarına engel olan unsurlardan birisi iletişim eksikliğidir. Ersoy ve Ala (2019) yapmış oldukları çalışmalarında yerel halk ile Suriyeli sığınmacı ve mültecilere ilişkin farkındalığın artırılması için etkinlikler planlanmasını önermektedir. Yapılan bu araştırmamızın sonuçlarına göre; kadın mültecilerin katılmış oldukları rekreatif etkinlikler aracılığıyla sosyal uyumda geçiş sürecinin kolaylaştırılmasında “rekreasyon”un önemli bir role sahip olduğu tespit edilmiştir. Gürsel, Güzel ve Yıldız'ın (2019) yapmış olduğu bir çalışma sonucunda kadınların spora teşvik edilmesinde rekreasyon alanlarının ve etkinliklerinin ulaşılabilir olmasının önemli olduğu ifade edilmiştir. Ayrıca rekreatif etkinlikler gibi spor temelli aktivitelere katılımda cinsiyetin motivasyon üzerinde önemli etkisi olduğu belirtilmiştir (Yıldız ve Polat, 2018). Dolayısıyla bireylerin fiziksel aktivitelere katılımlarda motivasyon kaynaklarının dikkate alınmasının kadınların sosyal uyum sürecinde etkili olabileceğini göstermektedir.

Sonuç olarak Suriyeli kadın mültecilere sunulan hizmetlerden birisi onların sosyalleşmesine yönelik etkinlikler olduğu tespit edilmiştir. Bu araştırma sonuçlarında da görüldüğü üzere rekreatif etknlikler sayesinde kadın mültecilerin sosyal uyum sorunun aşılmasında rekreatif etkinliklerin önemli bir yer tuttuğu görülmektedir. Bu sonuç rekreasyonel faaliyetlerin bireylerin rehabilitasyon süreçlerine de destek olduğu sonucunu desteklemektedir.

Kamu ve özel sektör tarafından rekreatif etkinlik hizmetleri sunulmaktadır. $\mathrm{Bu}$ etkinlikler düzenlenme ve planlanma aşamasında mülteci grupları da göz önünde bulundurulmalıdır. $\mathrm{Bu}$ durumun dezavantajlı kadın mülteci grubuna sosyal uyum sürecinde katkı sağlayacağından özellikle yerel yönetimlere bu tip rekreatif etkinliklerin hazırlanması ve uygulanması önerilmektedir.

Yayın Etiği: Mevcut çalışmanın yazım sürecinde "Yükseköğretim Kurumları Bilimsel Araştırma ve Yayın Etiği Yönergesi” kapsamında bilimsel, etik ve alıntı kurallarına uyulmuş olup; toplanan veriler üzerinde herhangi bir tahrifat yapılmamış ve bu çalışma herhangi başka bir akademik yayın ortamına değerlendirme için gönderilmemiştir. 
Esentaş, M., Güven, R.G. ve Güzel, P. (2020). Kadın mülteciler sosyal uyumu rekreasyonla aşıyor. Spor Bilimleri Araştırmaları Dergisi, 5(1), 35-43.

\section{KAYNAKLAR}

Angel, B., Hjern, A. \& Ingleby, D. (2001). Effects of war and organized violence on children: A study of Bosnian refugees in Sweden. American Journal of Orthopsychiatry, 71(1), 4-15. https://doi.org/10.1037/0002-9432.71.1.4.

Brey, E. T. \& Lehto, X. Y. (2007). The relationship between daily and vacation activities. Annals of tourism Research, 34(1), 160-180. https://doi.org/10.1016/j.annals.2006.08.001.

Yıldız, K. \& Polat, E. (2018). Basic motivation sources in sports. B. Tunçsiper and F. Sayın (Ed.,) In Critical Debates in Social Sciences. London: Frontpage Publications Limited.

Buz, S. (2008). Türkiye'deki sığınmacıların sosyal profili. Polis Bilimleri Dergisi, 10 (4), 1-14.

Büyüköztürk, Ş., Çakmak Kılıç, E., Akgün, Ö. E., Karadeniz, Ş. ve Demirel, F. (2008). Bilimsel araştırma yöntemleri. Ankara: Pegem Akademi Yayıncılık.

Demirbaş, H. ve Bekaroğlu, E. (2013). Evden uzakta olmak: Sığınmacıların/mültecilerin psikolojik sorunları ve alınacak önlemler. Kriz dergisi, 21(1), 11-24. https://doi.org/10.1501/Kriz_0000000334.

Ersoy, A. F. ve Ala, M. (2019). Suriyeli sığınmacı ve mültecilere ilişkin görüşler: Osmaniye'de nitel bir araştırma. Üçüncü Sektör Sosyal Ekonomi Dergisi, $\quad$ 54(3), http://dx.doi.org/10.15659/3.sektor-sosyal-ekonomi.19.09.1181.

Esentaş, M., Özbey, S. \& Güzel, P. (2017). Self-awareness and leadership skills of female students in outdoor Camp. Journal of Education and Training Studies, 5(10), 197-206. https://doi.org/10.11114/jets.v5i10.2600.

Gürsel, N., Güzel, P. ve Yıldız, K. (2019). Kadınların rekreasyonel faaliyetlere katılımında motivasyon ve engelleri ile ilgili durum tespiti; Manisa İli Örneği. Spor ve Performans Araştırmaları Dergisi, 10(2), 164-174. https://doi.org/10.17155/omuspd.471821.

Karadağ, Ö. ve Altıntaş, K. H. (2010). Mülteciler ve sağlık. TAF Preventive Medicine Bulletine, 9(1), 55-62.

Karademir, D. ve Doğan, M. (2019). Suriyeli mültecilerin mekânsal analizi: Şanlıurfa örneği. Coğrafya Dergisi, l(1), 111-124. https://doi.org/10.26650/JGEOG2019-0053.

Lu, L. \& Hu, C. H. (2005). Personality, leisure experiences and happiness. Journal of Happiness Studies, 6(3), 325-342.

Özbey, S., Işıkgöz, E., Esentaş, M. \& Güzel, P. (2018). Investigation of self-awareness levels of female students participating in international youth camp by different variables. Pamukkale Spor Bilimleri Dergisi, 9(3), 1-10.

Renner, W. \& Salem, I. (2009). Post-traumatic stress in asylum seekers and refugees from Chechnya, Afghanistan, and West-Africa: Gender differences in symptomatology and coping. Int J Soc Psychiatry, 55(2), 99-108. https://doi.org/10.1177\%2F0020764008092341.

Sezgin, A. A. ve Yolcu, T. (2016). Göç ile Gelen Uluslararası Öğrencilerin Sosyal Uyum ve Toplumsal Kabul Süreci. Humanitas-Uluslararasl Sosyal Bilimler Dergisi 4(7), 419-438. https://doi.org/10.20304/husbd.14985.

Stevens, C. A., Murphy, J. F., Allen, L. R. \& Sheffield, E. A. (2010). A Career with meaning: Recreational, parks, sport managament, hospitality, and tourism. USA: Sagamore Publishing L.L.C.

Tapmaz, Ç. (2012). Halk oyunları çalışmalarının ilköğretim beşinci sınıf (10- 11 Yaş Gurubu) öğrencilerinin sosyal uyum düzeylerine etkisi üzerine bir inceleme. Yüksek Lisans Tezi, Balıkesir Üniversitesi Sağlık Bilimleri Enstitüsü, Balıkesir.

Tütüncü, Ö., Aydın, İ., Küçükusta, D., Avcı, N. ve Taş, İ. (2011). Üniversite öğrencilerinin rekreasyon faaliyetlerine katılımını etkileyen unsurların analizi. Spor Bilimleri Dergisi, 2(22), 69-83.

Uluslararası Göç Örgütü. (2009). Göç terimleri sözlüğü. Erişim tarihi: 05.02.2019 http://www.goc.gov.tr/files/files/goc_terimleri_sozlugu(1).pdf . 
Esentaş, M., Güven, R.G. ve Güzel, P. (2020). Kadın mülteciler sosyal uyumu rekreasyonla aşıyor. Spor Bilimleri Araştırmaları Dergisi, 5(1), 35-43.

Yıldırım, A. ve Şimşek, H. (2013). Sosyal bilimlerde nitel araştırma yöntemleri. Ankara: Seçkin Yayıncılık.

Yılmaz, K. ve Altınkurt, Y. (2011). Göreve yeni başlayan özel dershane öğretmenlerinin kurumlarındaki çalışma koşullarına ilişkin görüşleri. Kuram ve Uygulamada Eğitim Bilimleri, 11(2), 635-650.

Zerengök, D., Güzel, P. \& Ozbey, S. (2018). The impact of leisure participation on social adaptation of international students. Journal of Education and Training Studies, 6(2), 1-9. https://doi.org/10.11114/jets.v6i2.2680.

Bu eser Creative Commons Atıf-GayriTicari 4.0 Uluslararası Lisansı ile lisanslanmıştır. 